\section{ZEW}

Zentrum für Europäische Wirtschaftsforschung GmbH

Centre for European Economic Research

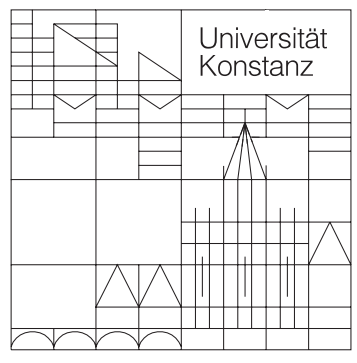

Rechts-, Wirtschafts- und Verwaltungswissenschaftliche Sektion Fachbereich

Wirtschaftswissenschaften

Diskussionspapiere der DFG-

Forschergruppe (Nr.: 3468269275):

Heterogene Arbeit: Positive und Normative Aspekte der Qualifikationsstruktur der Arbeit

Anton L. Flossmann

Winfried Pohlmeier

Causal Returns to Education: A Survey on Empirical Evidence for Germany

Mai 2007 
Diskussionspapier der Forschergruppe (Nr.: 3468269275) "Heterogene Arbeit: Positive und Normative Aspekte der Qualifikationsstruktur der Arbeit"

Nr. 07/05, Mai 2007

\title{
Causal Returns to Education: A Survey on Empirical Evidence for Germany
}

Corresponding Author

\section{Anton L. Flossmann}

University of Konstanz

Department of Economics

Box D 617

78457 Konstanz

Germany

phone: $+49-7531-88-4242$

fax : $+49-7531-88-4450$

mail : anton.flossmann@uni-konstanz.de

\section{Winfried Pohlmeier}

University of Konstanz

Department of Economics

Box D 124

78457 Konstanz

Germany

phone : $+49-7531-88-2660$

fax : +49-7531-88-4450

mail : winfried.pohlmeier@uni-konstanz.de

\begin{abstract}
:
This paper surveys the empirical evidence on causal effects of education on earnings for Germany and compares alternative studies in the light of their underlying identifying assumptions. We work out the different assumptions taken by various studies, which lead to rather different interpretations of the estimated causal effect. In particular, we are interested in the question to what extend causal return estimates are informative regarding educational policy advice.

Despite the substantial methodological differences, we have to conclude that the empirical findings for Germany are quite robust and do not deviate substantially from each other. This also holds for the few studies which rely on ignorability conditions, regardless of whether they use educational attainment as a continuous treatment variable or as a discrete treatment indicator. Own estimates based on the matching approach indicate that the selection into upper secondary schooling is suboptimal.
\end{abstract}

JEL Classification : C21, J24, J31

Keywords : returns to education, potential outcome approach, instrumental variables, unconfoundedness, control function approach

Download/Reference : http://www.wiwi.uni-konstanz.de/forschergruppewiwil 


\title{
Causal Returns to Education: A Survey on Empirical Evidence for Germany
}

\author{
Anton L. Flossmann \\ University of Konstanz, CQMSR \\ Winfried Pohlmeier * \\ University of Konstanz \\ ZEW, CQMSR
}

this version

April 13, 2006

\begin{abstract}
This paper surveys the empirical evidence on causal effects of education on earnings for Germany and compares alternative studies in the light of their underlying identifying assumptions. We work out the different assumptions taken by various studies, which lead to rather different interpretations of the estimated causal effect. In particular, we are interested in the question to what extend causal return estimates are informative regarding educational policy advice.
\end{abstract}

Despite the substantial methodological differences, we have to conclude that the empirical findings for Germany are quite robust and do not deviate substantially from each other. This also holds for the few studies which rely on ignorability conditions, regardless of whether they use educational attainment as a continuous treatment variable or as a discrete treatment indicator. Own estimates based on the matching approach indicate that the selection into upper secondary schooling is suboptimal.

JEL classification: C21, J24, J31

Keywords: returns to education, potential outcome approach, instrumental variables, unconfoundedness, control function approach

\footnotetext{
${ }^{*}$ Corresponding author. Department of Economics, Box D124, University of Konstanz, 78457 Konstanz, Germany. Phone ++49-7531-88-2660, Fax -4450, email: winfried.pohlmeier@unikonstanz.de. This paper is a completely revised and updated version of Pohlmeier's (2004) survey presented at the BMBF-Workshop "Investition in Humankapital", Bonn, June 7th, 2004. Financial support by the DFG through research group 'Heterogenous Labor" at the University of Konstanz and the ZEW, Mannheim, is gratefully acknowledged.
} 


\section{Introduction}

It is beyond dispute among economists as well as non-economists, that educational attainment and individual earnings are positively correlated. This observation is mostly explained by the general notion that education has a productivity enhancing effect which is valued by the labor market through higher wages. This is why the returns to education, here simply defined as the earnings differences related to difference in educational attainment, have become a popular monetary measure to assess the quality of a certain educational training in the light of the needs of the labor market.

However, classical return estimates obtained from least squares estimation of earnings functions, which do not take into account the heterogeneity of individual returns and the endogeneity of the individual schooling decision, are less informative for educational policy devices. First, the fixed coefficient specification assumes that the individual returns are identical for all individuals with the same educational degree. Furthermore, they are identical across different subpopulations, e.g an employee with a lower secondary degree could (ceteris paribus) expect as much income as an employee with an upper secondary degree if he or she had graduated from upper secondary school. More important, conventional return estimates do not provide any information to what extent more education is causally responsible for more income. This is because they summarize an overall effect of education on earnings which depend on a self-selection process due to individual differences in benefits, preferences, and costs of education that drive the schooling decision. In order to learn anything regarding the impact of the quality and/or quantity of educational attainment on individual earnings, which solely can be attributed to the educational attainment and not to self-selectivity, causal returns to education have to be estimated. Based on the potential outcome approach going back to Roy (1951) and Rubin (1974), the research interest has been centered around estimating causal returns to education which compare earnings of a worker with a given educational attainment to a counterfactual situation, i.e. the worker's earnings in case he had received a different educational attainment.

This paper provides a selective survey of recent studies on the causal effects of education on earnings for Germany. Besides obvious differences considering the data base used as well as the definition of the education variable, the studies differ in 
terms of the underlying assumptions that identify the causal effect, the estimation method, and the type of causal effect estimated. We work out the methodological differences between various studies and the consequences for the interpretation of their empirical findings in Section 2. In Section 3 we discuss studies in the tradition of the Becker-Mincer type of human capital earnings function which uses schooling as a continuous dependent variable. The case of the causal impact of educational career choices within the structured school system, where educational input (program choice) is taken as a discrete treatment variable is presented in Section 4. Section 5 draws attention to further aspects of the impact of education on earnings including the role of program and income risk, overeducation, and the impact of school quality on earnings. Section 6 concludes and gives an outlook on future research.

\section{Causal Returns}

Although estimates of the returns to education generally rely on estimating a relationship between an individual's log earnings, $\ln Y$, and a variable which proxies the individual's educational attainment, $S$, the underlying assumptions and the resulting interpretation of the return estimates are rather different. To clarify these differences, we will use the correlated random coefficient representation

$$
\ln Y=\alpha+\beta S,
$$

which nests a number of different specifications. Here $\alpha$ and $\beta$ represent random variables correlated with observable and unobservable individual attributes (i.e. experience, gender, cognitive and noncognitive skills, preferences, costs of education etc.). Although the earnings function is usually motivated by the reasoning of human capital theory, it can simply be taken as a hedonic price equation relating educational attainment to the individual's wage. If educational attainment $S$ is conventionally measured in terms of years of schooling ${ }^{1}$, the returns to education are given by

$$
\frac{\partial \ln Y}{\partial S}=\left.\beta \approx \ln Y\right|_{S=s+1}-\left.\ln Y\right|_{S=s}
$$

\footnotetext{
${ }^{1}$ Studies on the German school system usually use the number of school years required to obtain the highest degree the individual holds.
} 
Thus, the return rate is heterogeneous and varies across individuals. The focus of interest is no longer a single coefficient, but different moments of $\beta$. The mean causal return rate $\mathrm{E}[\beta]$ (mean partial derivative) reflects the effect of education on earnings in the sense of a laboratory experiment, because it denotes the expected income increase that arises from an one year increase of educational training of an individual that is randomly drawn from the population. In terms of the nomenclature of the econometric evaluation literature, $\mathrm{E}[\beta]$ is nothing else but the average treatment effect for the case of a continuous treatment variable. Due to the selfselection, the expected return rates for individuals with different schooling levels are different; $\mathrm{E}\left[\beta \mid S=s_{0}\right] \neq \mathrm{E}\left[\beta \mid S=s_{1}\right]$. Even without imposing nonlinearities between log earnings and schooling, e.g. through polynomials in $S$, the return rates vary across education levels.

The classical Mincer type of earnings function arises as a special case of (2.1) for $\alpha=\alpha_{0}+\varepsilon$ and $\beta=\beta_{0}$ :

$$
\ln Y=\ln Y(S)=\alpha_{0}+\beta_{0} S+\varepsilon,
$$

where $\alpha_{0}$ and $\beta_{0}$ are fixed parameters. Note, that selfselection still generates heterogeneous return rates

$$
\ln Y(S=s+1)-\ln Y(S=s)=\beta_{0}+\varepsilon(S=s+1)-\varepsilon(S=s),
$$

unless the correlation between the error term and schooling is ruled out by assumption. Turning the argument around, if the individual heterogeneity represented here solely by $\varepsilon$ is uncorrelated with $S$, the return rate is constant across individuals a property that is empirically rather improbable. Only under this very restrictive assumption, least squares estimation yields consistent return estimates that have a causal interpretation. As a benchmark we present in Table 1 conventional least squares estimates of the return rate for Germany based on different samples and time periods. 
Table 1: Least Squares Return Estimates for Germany

\begin{tabular}{lcccc} 
& $\beta_{0}$ & males/females & year & sample \\
\hline Franz (2002) & 0.072 & $\mathrm{~m}$ & $84-93$ & GSOEP-West \\
Pischke \& Krueger (1995) & 0.075 & $\mathrm{~m}$ & 88 & GSOEP-West \\
& 0.071 & $\mathrm{~m}$ & 88 & DDR \\
& 0.082 & $\mathrm{f}$ & 88 & GSOEP-West \\
& 0.085 & $\mathrm{f}$ & 88 & DDR \\
Pischke \& DiNardo (1997) & $0.064-0.072$ & $\mathrm{~m}+\mathrm{f}$ & $79,85 / 6,91 / 2$ & BIBB-IAB-West \\
Pfeiffer (1994) & $0.058-0.085$ & $\mathrm{~m}$ & $84-89$ & GSOEP-West \\
Steiner \& Lauer (2000) & 0.08 & $\mathrm{~m}$ & $84-97$ & GSOEP-West \\
& 0.10 & $\mathrm{f}$ & $84-97$ & GSOEP-West \\
Jochmann \& Pohlmeier (2004) & 0.061 & $\mathrm{~m}$ & 01 & GSOEP-West \\
\hline
\end{tabular}

GSOEP - German Socio-Economic Panel, BIBB-IAB - Survey on educational and vocational attainment and career of the Bundesinstitut für berufliche Bildung and the Institut für Arbeitsmarkt und Berufsforschung

The estimates are based on traditional specifications of the earnings function with the number of school years as explanatory variable. If we assume that the attenuation bias resulting from a mismeasurement of the educational attainment variable is negligible and education is positively correlated with the error term, the least squares estimates are upward biased estimates of $\beta_{0}$. In fact, least squares consistently estimates $\beta_{0}+\delta$, where $\delta>0$ is the coefficient of the linear predictor of $\varepsilon$ on $S$. Under these conditions and the assumption of a deterministic $\beta$, the least squares estimates can be regarded as an upper bound for the average causal return rate in the model with a continuous schooling variable. In fact, a random $\beta$ generates an additional upward bias (see Card (2001) for a proof).

For a structured school system as the German one, treating educational attainment as a continuous variable is not utterly convincing, even if educational attainment can be measured without error. Although the conventional concept of capturing educational attainment by the number of school years is closer to the idea of human capital accumulation, it is hardly consistent with a structured school system, because it assumes that an educational attainment of a certain quantity is equivalent 
for any school track, e.g. nine years at the lower secondary school (Hauptschule) is of the same quality in terms of income expectations and career options as nine years at a school leading to a medium or upper secondary school degree (Realschule or Gymnasium). Thus differences in the quality of educational attainment are completely ignored. Observed differences in earnings between graduates from different school tracks are also the result from differences in curriculae, educational background of teachers, school infrastructure, and peer groups. Therefore, in the case of the structured school system, earnings differences between graduates from different school tracks should be interpreted as effects of rather different educational programs where the duration of the program is just one distinguishing element.

The random coefficient specification (2.1) is also consistent with the potential outcome approach, if the causal return of participating in an educational program is to be evaluated in comparison to some reference program. Let $\ln Y_{0}$ be the potential earnings obtained from completing reference program $(S=0)$ and $\ln Y_{1}$ be the potential earnings in the case of completing the alternative program successfully $(S=1)$. Then observed earnings take on the form $\ln Y=S \ln Y_{1}+(1-S) \ln Y_{0}$ with $\alpha \equiv \ln Y_{0}$ and $\beta \equiv \ln Y_{1}-\ln Y_{0}$. Regardless of defining the education variable as a continuous treatment variable (years of schooling) or as a discrete treatment indicator (dummy variable for school track) within a structured school system, it is important to emphasize, that in the case of heterogeneous returns it is no longer meaningful to refer to the causal effect, because different parameters of interest for policy analysis can be defined.

Inherent to the estimation of causal effects within the potential outcome approach is the problem of identifying the counterfactual evidence. The literature on econometric evaluation offers a variety of strategies to overcome this identification problem, each hinging on specific, untestable assumptions. The use and applicability of these different methods is restricted in the way in which the causal effect of interest is defined, assumptions about individual heterogeneity of treatment effects are made and data are available. In the following we discuss briefly two popular identification methods for the mean causal parameters: the method of instrumental variables or control function approach, and the identification via ignorability assumptions. Both strategies have been applied to estimate causal returns to education and causal program effects for Germany. 
The formulation of the random coefficient specification in terms of a traditional earnings function with fixed coefficients

$$
\ln Y=\alpha_{0}+\beta_{0} S+\omega
$$

with $\alpha_{0} \equiv \mathrm{E}[\alpha]$ and $\beta_{0} \equiv \mathrm{E}[\beta]$, seems to call for a standard instrumental variables (IV) approach, since the error term $\omega \equiv \alpha-\alpha_{0}+\left(\beta-\beta_{0}\right) S$ is by construction correlated with the regressor.

The IV approach, as well as control function methods, rest on the assumption that there exist one ore more instruments which are correlated with the education variable but uncorrelated with the error term. Since the instrument affects earnings only indirectly via the education variable, the causal effects can be identified by the variation of the instrument. Popular examples used in the literature are educational degree of parents, number of siblings, or proximity to the educational institution. Because correlation between instruments and unobserved ability cannot be ruled out in many cases, the validity of the instruments has to be viewed critically. Since the validity of the instruments is in principle untestable, empirical support can only be obtained through external studies.

Which causal parameter is identified by IV estimation depends on the specific assumptions about underlying heterogeneity. If the returns to education are the same for all individuals, IV identifies and consistently estimates the average causal return rate. In a heterogeneous response model, IV no longer guarantees to identify any of the mean causal effects. Heckman (1997) shows that if unobservable factors, like ability, drive educational choices and outcome, the average causal return to education is only identified by imposing the restrictive assumption that selection is not based on unobservable gains of the individuals.

On the other hand, the ignorability approach assumes that the researcher observes all relevant variables influencing both the educational choice of the individuals and the earnings outcome. Heckman \& Robb (1986) classify this assumption as the selection on observables assumption. It basically means, that once having controlled for all observable factors that potentially drive schooling choice and earnings, individuals select themselves randomly into the corresponding educational treatment. Consequently, the estimation approaches relying on the ignorability condition require rich 
datasets from which the researcher is able to measure all relevant covariates. If, conditional on the observed factors, there is additional unobserved heterogeneity in the treatment effects, no causal parameter of interest can be identified. Therefore, applications based on the ignorability approach when estimating causal effects of schooling using standard socio-economic surveys such as the GSOEP or the BIBBIAB data, are subject to the critique that obvious factors determining schooling choice such as intelligence (IQ) and measures for cognitive and non-cognitive skills, if available at all, are rather crude and may not guarantee the ignorability assumption to hold.

\section{Causal Returns based on Continuous Schooling Variables}

By far, the majority of the studies estimating some causal concept of the returns to education for Germany use a continuous measure of educational attainment. The most frequently used is the number of school years required to obtain the highest degree. Lauer \& Steiner (2000) estimate the returns to education by IV-methods for the fixed coefficient case. Instruments used are for example parental education, occupational position of the father or, if the family lives in an urban or rural community. The results vary between $6.6 \%$ and $14.8 \%$ for the male population. Their IV-estimates are rather sensitive to the instruments used, but they do not depart much from least squares estimates. One explanation for this can be the existence of weak instruments. In this case, IV estimates are biased towards the least squares estimates (see for example Staiger \& Stock (1997)).

Skarupke (2005) applies a Panel Random Effects IV approach by Hausman and Taylor on the basis of GSOEP-West data for the years 1988-1998. The estimated returns to education for males range between $12.29 \%$ and $15.38 \%$, depending on the specification of the earnings function and whether a balanced or unbalanced panel is used. The endogeneity problem in this model arises because of the correlation between the schooling variable and the individual random effect. 
Jochmann \& Pohlmeier (2004) estimate the average return to education for an earnings function with a continuous schooling variable under the assumption of heterogeneous returns. The instruments used are upper secondary school density (DENS), number of siblings $(S I B)$ and the unemployment rate at the time of graduation $(U R G)$. All three types of instruments can be interpreted along with Card $(1995,2001)$ as proxies for individual differences in the costs of schooling. As can be seen from Table 2 below, the IV estimates for the average causal return to education strongly depend on the choice of instruments. The average causal effect lies above the traditional (not causally interpretable) return rate. Moreover, most of the instruments turn out to be weak (see for example Bound, Jaeger \& Baker (1995)), but alternative k-class estimators with superior small sample properties do not change the results substantially.

Table 2: IV Return Estimates Using Different Instruments

\begin{tabular}{lccccc}
\hline Model & $L S$ & $I V$-DENS & $I V$-URG & $I V$-SIB & $I V$-ALL \\
\hline SCHOOL & 0.061 & 0.097 & 0.054 & 0.075 & 0.086 \\
& $(0.003)$ & $(0.019)$ & $(0.070)$ & $(0.016)$ & $(0.013)$ \\
\hline \# Instruments & 4 & 2 & 2 & 8 \\
1. Stage F-Test & 10.52 & 1.38 & 26.52 & 11.46 \\
\hline
\end{tabular}

Source: Jochmann \& Pohlmeier (2004), p. 16, standard errors in parenthesis, GSOEP-West 2001, $\mathrm{n}=1711$

However, as was pointed out in the previous section, under heterogenous returns IV estimation does no longer guarantee to identify the mean causal return to eduction. Based on a simple structural model of educational choice leading to the random coefficient specification, Card (2001) shows that the identification of the mean causal effects is only possible under strong distributional assumptions (e.g. independence of marginal benefits and marginal costs of schooling). Since in his model the random coefficient beta basically represents unobserved differences in the marginal benefits of schooling, variables which are correlated with the marginal costs of education, but are independent of the marginal benefits, can serve as valid instruments. Proposed instruments in the literature for example are local proximity to college or the regional unemployment rate at the time of graduation. as well as participation and non-participation in educational reforms, which are assumed to have influenced the 
educational choice. $^{2}$

Another approach is followed by Heckman \& Vytlacil (1998), who assume a correlated random coefficient model and apply it to Card's model of schooling. The crucial assumptions are that the treatment variable is continuous, and the unobserved interaction between schooling and the individual return to education does not depend on the instruments. Wooldridge (2000) relaxes this assumption in order to allow for discrete treatments at the expense of additional parametric assumptions.

On the basis of GSOEP data, Schnabel \& Schnabel (2002) present estimates of the mean causal return rate within the correlated random coefficient framework based on a control function approach. In order to account for unobserved heterogeneity within a family, they construct a siblings sample and apply family fixed effects and family correlated random-effects estimation. Since the siblings sample contains foremost young persons, their return estimates are relatively low compared to conventional estimates based on full samples. The main result, however, is that the returns to education depend significantly on factors like family background or gender. Therefore they conclude that policies attempting to equalize educational opportunities remain an important task, since individuals whose parents have a high educational degree tend to have lower returns to schooling and higher wages than persons with less-educated parents.

Wooldridge (2004) identifies the average causal effect in a correlated random coefficient framework under ignorability conditions. Following his approach, Maier, Pfeiffer \& Pohlmeier (2004) estimate a mean causal return rate of $8.7 \%$ based on a cross-section of the BIBB-IAB data for German workers. Although their estimation approach relies on rather different identifying assumptions, the estimates are surprisingly close to the standard IV-estimates.

While identification of the average return to education under individual heterogeneity by means of instrumental variables requires strong assumptions, Imbens \& Angrist (1994) and Angrist, Imbens \& Rubin (1996) show that IV estimation can be meaningful in the presence of individual heterogeneity despite of a potential correlation between the error and the instrument. Under fairly weak assumptions, IV

\footnotetext{
${ }^{2}$ See for example Pischke \& Von Wachter (2005) for the impact of compulsory schooling in Germany.
} 
identifies with the Local Average Treatment Effect (LATE) an interpretable causal effect:

$$
\begin{aligned}
\Delta_{\text {LATE }} & =\mathrm{E}[\beta \mid S(Z=1)-S(Z=0)=1] \\
& =\frac{\mathrm{E}[\ln Y \mid Z=1]-\mathrm{E}[\ln Y \mid Z=0]}{\mathrm{E}[S \mid Z=1]-\mathrm{E}[S \mid Z=0]},
\end{aligned}
$$

where $Z$ represents a binary instrument and $S(Z=j), j=0,1$ is the schooling variable as a function of $Z$. In addition to the exclusion restriction, identification of the LATE requires a monotonicity condition with respect to the effect of the instrument on the treatment. $\Delta_{L A T E}$ measures the average causal effect for those individuals who change their treatment status due to a variation in the instrumental variable.

Since in the presence of unobserved heterogeneity the estimation of the average causal return can only be targeted under restrictive assumptions, IV estimates should be more conservatively interpreted as estimates of the LATE. Ichino and WinterEbmer $(1999,2004)$ present estimates of the LATE for Germany using different instruments. On the basis of the LATE-interpretation and two instruments (parental educational background and an indicator of father's serving in the military during World War II) Ichino \& Winter-Ebmer (1999) estimate upper and lower bounds for the returns to education in Germany. The lower bound is obtained by estimating the LATE for those individuals who change their human capital investments due to a change in the parental educational background, since it is assumed that this instrument affects less able children from poor families. The second instrument measuring the fact of father's serving in the military during World War II, is likely to affect highly able but liquidity constrained individuals. The corresponding LATE estimate can therefore be regarded as an upper bound of the individual returns to schooling. The estimated interval for the average causal return to schooling ranges between $4.8 \%$ and $11.7 \%$. Since both instruments could affect other individuals with low or high returns to schooling than the previously discussed groups, the estimated range is very conservative. Nevertheless, it can be seen as further evidence for heterogenous returns to education in Germany. Ichino \& Winter-Ebmer (2004) estimate the average return to education for those individuals who had to reduce their educational investments in human capital due to World War II. As instruments they use a 1930-1939 birth cohort indicator, an indicator of father's serving in the military during World War II and an indicator for high school education of the father. Depending on the instruments being used, the estimated returns to education 
range between $9.4 \%$ and $16.2 \%$. These returns are interpreted as measures for the long-run educational costs of the war.

One of the problems estimating the LATE is that the parameter refers to a hypothetical population, namely the compliers, which cannot be identified on the basis of observational data. With the help of an additional assumption however, information can be obtained with respect to the target population of the LATE parameter. Thereby, it is assumed that the returns to education are constant for certain subgroups in the population. Based on this discrete heterogeneity assumption, Becker \& Siebern-Thomas (2001) replicate a study of Kling (2001) for the German case. By means of observable factors describing the parental background, they identify the population subgroup which reacts strongest to a variation of the instrument (proxy for school infrastructure). Their results lead to the conclusion that subpopulations with a poor family background and therefore high credit constraints especially drive the estimator. Besides the limited identifiability of the target population, an additional drawback arises from the fact that LATE-estimates are only interpretable in the case of one discrete instrument. The use of more than one instrument does not lead to a straightforward interpretation, since other instruments would have to be held fixed. Nevertheless, the LATE-interpretation is used to explain the tendency of higher IV-estimates compared to LS-estimates. Card (2001) favors the hypothesis that instruments which constitute interventions on the supply side of human capital, have an impact especially on less educated individuals. It is thereby assumed, that the corresponding persons face high marginal costs but at the same time have higher returns to education than the average. For Germany, the same interpretation is followed by Becker \& Siebern-Thomas (2001). The range of the IV-estimates (9.2\%-13.8\%) clearly exceeds the corresponding range of their LS-estimates $(6.6 \%$ $6.7 \%)$.

\section{Causal Program Returns}

The basic setup for measuring causal treatment effects is the potential outcome model. Applying this model to a discrete education indicator, let $\ln Y_{j}$ be the potential outcome under treatment status $j$, where $j \in \mathcal{S}$. In the context of multiple treatments let $\mathcal{S}=\{0,1,2, \ldots, m\}$ be the set of indices for the corresponding treatment regimes. $S \in \mathcal{S}$ is a random variable indicating the treatment level received. 
The actually observed outcome is $\ln Y=\ln Y_{S}$.

The average causal return to education of a higher degree $l$ compared to a lower degree $m$ is defined as:

$$
\Delta_{A T E}^{l, m}=\mathrm{E}\left[\ln Y_{l}-\ln Y_{m}\right]
$$

Obviously, in this definition a natural ordering (e.g. $m$ and $l$ are sequential programs) is assumed. Alternatively, we may interpret (4.1) as the expected income difference between program choices. This parameter measures the average causal effect of schooling degree $l$ compared to $m$ on the outcome of an individual randomly chosen from the population. In the evaluation literature this parameter is defined as the Average Treatment Effect (ATE).

A further parameter of interest for the evaluation of educational policies is the Average Treatment Effect on the Treated (TT):

$$
\Delta_{T T}^{l, m}=\mathrm{E}\left[\ln Y_{l}-\ln Y_{m} \mid S=l\right]
$$

This parameter represents the average causal effect of schooling degree $l$ on the participants with school degree $l$, compared to the outcome which would arise if they obtained school degree $m$. If, for example, $l$ represents upper secondary schooling and $m$ stands for technical school, then $\Delta_{T T}^{l, m}$ measures the return to education of the $13^{\text {th }}$ school year for the individuals attending the upper secondary school.

Alternatively, we can define the Treatment Effect on the Untreated as

$$
\Delta_{T U T}^{l, m}=\mathrm{E}\left[\ln Y_{l}-\ln Y_{m} \mid S=m\right]
$$

Referring to the example from above, $\Delta_{T U T}^{l, m}$ measures the expected rise in earnings for employees with a technical school degree, if they had completed a $13^{\text {th }}$ year of schooling. Therefore, $\Delta_{T T}^{l, m}$ measures the average success on the labor market for those who participated in an educational program and $\Delta_{A T E}^{l, m}$ measures the success on the labor market as an average across participants and nonparticipants. Finally, $\Delta_{T U T}^{l, m}$ gives information about the success of the nonparticipants, if they had been forced to participate in an educational treatment. Comparing the three causal parameters may reveal useful information for policy analysis. Heckman \& Li (2003) for example refer to the difference between $\Delta_{T T}^{l, m}$ and $\Delta_{A T E}^{l, m}$ as to the "sorting gain". Let 
the treatment be upper secondary schooling $(l)$ compared to intermediate schooling $(m)$. A positive sorting gain would indicate that persons with higher ability are allocated to the appropriate educational institution. On the other hand, a negative sorting gain indicates that there may be individuals at the intermediate secondary level who should attend upper secondary school according to their abilities.

Furthermore, in combination with the LATE, the mean causal effects give information on whether a policy targets the right individuals. For example, if the instrument is an educational treatment like tuition fees, which induce some individuals to revise their decision to attain a university degree, $\Delta_{L A T E}^{l, m}$ measures the return to education of this population subgroup. A comparison between $\Delta_{T T}^{l, m}$ and $\Delta_{L A T E}^{l, m}$ gives information about the direction of the selection effect. For $\Delta_{T T}^{l, m}>\Delta_{L A T E}^{l, m}$ the reform can be viewed as successful, because it has motivated more productive individuals to continue attending the university.

The ignorability approach identifies the mean causal effects according to the following conditional independence assumption (CIA):

$$
\begin{aligned}
& \left(Y_{l}, Y_{m}\right) \perp S \mid\{X=x, S=m, l\}, \forall x \in \mathcal{X}, \forall m, l \in \mathcal{S} \\
& 0<\operatorname{Pr}[S=l \mid X=x]<1, \forall x \in \mathcal{X}, l \in \mathcal{S}
\end{aligned}
$$

where $X$ is a vector of observable covariates with outcome space $\mathcal{X}$ and $\perp$ denotes 'independence'. ${ }^{3}$ Condition (4.5) requires a common support. The CIA basically means, that given certain covariates $X$, schooling choice is ignorable. As a consequence, conditional on the observed covariates, the ATE, TT and the TUT defined above are the same. They differ only in the way the distribution of the observable factors differs across the population subgroups of interest.

The estimation methods based on the ignorability condition differ with respect to the parametric assumptions about the earnings equation. The simple regression approach (including all covariates as additional controls) constitutes a parametric variant. On the other hand, matching methods do not require parametric assumptions about the relation between the education variable and the outcome of interest,

\footnotetext{
${ }^{3}$ One could weaken the assumptions even more by restricting the conditional independence to hold only for certain moments. An example would be the widely used conditional mean independence assumption. However, it is often difficult to argue from a theoretical point of view why mean independence should hold and the CIA not. See Lechner (2001).
} 
and therefore constitute an example for a nonparametric estimation approach. For an overview of these methods see Imbens (2004).

Due to data limitations, the number of studies using the ignorability assumption to estimate causal educational program effects is rather negligible. A notable example is the study by Blundell, Dearden \& Sianesi (2005) for the United Kingdom using matching methods. Mainly for illustrative purposes, we also invoke the ignorability assumption and estimate average causal returns to schooling by matching methods using the 2001 wave of the GSOEP. In our sample we include all German men which are full-time employed and live in West-Germany. Apart from the standard covariates on the socio-economic background, additional variables indicating the individual's activeness in music and sports have been added to proxy individual motivation and therefore to account for unobserved noncognitive skills. The treatment variable consists of three different categories, reflecting the special institutional setting of the German school system. The treatment variable is defined as the highest school degree obtained by the individual: secondary school, intermediate/ technical school, and upper secondary school. The ATE, TT and TUT are estimated for each binary combination of treatment categories (Table 3 below).

Table 3: Average Causal Returns for the German School Tracks

\begin{tabular}{l|c|c|c}
\hline compared school tracks & $\Delta_{T U T}$ & $\Delta_{A T E}$ & $\Delta_{T T}$ \\
\hline second./upper second. & $.061(.013)$ & $.068(.011)$ & $.080(.015)$ \\
second./interm. & $.076(.034)$ & $.094(.023)$ & $.114(.026)$ \\
interm./upper sec. & $.065(.016)$ & $.061(.013)$ & $.057(.018)$ \\
\hline
\end{tabular}

Source: Own computations, estimation by NN-matching, standard errors in parenthesis, $\mathrm{n}=1054$

For the first two educational treatment variables, the TT is larger than the ATE, which gives rise to the conclusion that individuals are allocated to the appropriate institutions according to their abilities. Surprisingly, for the third pair of comparison (interm./upper sec.), we find that the average treatment effect is larger than the treatment effect on the treated. This indicates that the selection of students in the two groups is inefficient. A random selection of students having at least a secondary degree in the last three years of the Gymnasium would yield higher returns to schooling. Because the TT is lower than the ATE for the third treatment variable 
(intermediate vs. upper secondary school), there are workers with intermediate degree and high potential who would have gained more by attending upper secondary school. At any rate, this finding does not contradict the critics of selection into the school tracks after the fourth grade, raising doubts about the suitability of the selection process at this early stage of the educational career.

While the standard IV approach generally does not identify average causal effects when returns to education are heterogeneous, the control function approach provides a solution without the need of imposing unrealistic assumptions about the individual schooling choice. A drawback of the control function approach is that an equation for the educational choice has to be specified. Based on the parameters of the choice equation, control functions are estimated and added as control variables to the outcome equation. The probably most prominent example for a control function approach is Heckman's (1979) two stage estimator ('Heckit'), which heavily depends on parametric assumptions. Modern control function approaches attempt to relax the assumptions on the functional form of the control function and use semiparametric selection models (see Powell (1994) for a survey). A serious problem of control function estimators remains the choice of appropriate instruments to achieve identification. A valid instrument has to enter the selection equation but not the earnings function. For most of the variables used in the literature, the choice of such an exclusion restriction is as hard as the search for valid instruments in the standard IV framework. In many cases, it can be convincingly argued that the instrument used in the selection equation can also serve as an explanatory variable for individual earnings.

Recently, the Local Instrumental Variable (LIV) approach has been introduced as a new variant to estimate the ATE, TT and TUT in a nonparametric selection model by Heckman \& Vytlacil (2005a, 2005b). Interestingly, Vytlacil (2002) shows the equivalence between imposing a nonparametric version of the standard selection model and the LATE assumptions imposed by Imbens \& Angrist (1994). By means of the LIV method, it is possible to estimate the marginal treatment effect (MTE), which measures the mean return for the individuals who are indifferent between two treatment regimes. It can be shown that all treatment parameters, matching estimators, and IV-estimators can be written as weighted averages of the MTE. Maier (2004) applies the LIV-method to estimate the effect of a university degree on wages compared to vocational training. The unemployment rate at the year of graduation 
serves as the identifying instrument. His estimates for the program returns are: $\Delta_{T U T}=.564, \Delta_{A T E}=.569$ and $\Delta_{T T}=.640$. Although there seems to be a positive sorting gain $\left(\Delta_{T T}>\Delta_{A T E}\right)$, the difference turns out to be insignificant.

\section{Some Neglected Issues}

\subsection{Overqualification}

Overeducation can be defined as the part of a worker's overall educational attainment that is not required to perform the current job. In this sense, the returns to overeducation shed light on the efficient use of education and skilled labor. Obviously, overeducation, as a fuzzy concept, is difficult to measure. In the literature, a range of subjective and objective measures for overeducation have been proposed. Subjective measures are more or less based on the worker's self-assessment of the skills required for his current position compared to his own educational attainment. Objective measures usually relate the legally required education for a worker's current position to the actual level of education. If available, combinations of the two extreme concepts are conceivable and require that both a subjective and an objective criterion have to be satisfied to define a worker as being overqualified. Based on 25 econometric studies, Groot \& van den Brink (2000) show in their meta-analysis that the estimates of (noncausal) returns to overeducation is rather sensitive to the measurement concept. However, in general they find broad international evidence that the returns to overeducation are considerably lower than the returns to required schooling.

To our knowledge, the studies by Jochmann \& Pohlmeier (2003) and Maier, Pfeiffer \& Pohlmeier (2003) are the only studies explicitly focussing on the causal effects of overeducation. While the former study treats overeducation as a binary event within a Bayesian evaluation framework, the latter study is based on a random coefficient earnings function for specific skill groups where schooling additional to the required schooling serves as the continuous treatment variable. Table 4 below contains the estimation results for male fulltime employed German workers (BIBB-IAB, 1998/99 sample) based on the unconfoundedness approach proposed by Wooldridge (2002, 2004). 
Table 4: Causal Returns to Overeducation

\begin{tabular}{l|rr}
\hline Skill Group & $\mathrm{E}[\beta]$ & \\
\hline Unskilled & .049 & $(1.18)$ \\
Vocational training & .082 & $(23.25)$ \\
Foreman, sen. craftsman & .061 & $(12.58)$ \\
University graduates & .237 & $(7.66)$ \\
\hline
\end{tabular}

Source: Maier et al. (2003). p.144, t-values

in parenthesis, trimmed observations

For the group of skilled and high skilled workers, they find no evidence that the average causal returns to overeducation are lower than the average causal returns to required education. This somewhat stands in contrast to the evidence found for the majority of traditional studies. Therefore they conclude that overeducation should be viewed as a rational investment strategy, especially by a large part of the group of skilled workers. Only for the group of unskilled workers do the average returns to overeducation turn out to be very low. However, Maier et al. (2003) find considerable heterogeneity in the returns to overeducation, as well as in the returns to required education.

\subsection{Income Risk and Program Risk}

Heterogeneity and self-selectivity also have serious implications for the assessment of the quality of educational policies beyond the econometric problem of identifying causal mean returns. Focussing only on mean returns ignores that the quality of educational policies also depends on the riskiness of the educational programs supplied, i.e. on $\mathrm{V}[\beta]$, the variance of the causal return effect. If policy makers are risk averse, they should also be concerned about the risk of an educational program. In order to estimate the program risk, additional identifying assumptions are required. For the case of a comparison of two educational programs (binary treatment model) the information on the covariance between $\alpha$ and $\beta$ is equivalent to information on the correlation between the potential outcomes $Y_{0}$ and $Y_{1}$.

$$
\mathrm{V}\left[\ln Y_{1}-\ln Y_{0}\right]=\mathrm{V}\left[\ln Y_{1}\right]-\mathrm{V}\left[\ln Y_{0}\right]-2 \operatorname{Cov}[\alpha, \beta]
$$

Pohlmeier \& Flossmann (2005) point out that the term $\mathrm{V}\left[\ln Y_{1}\right]-\mathrm{V}\left[\ln Y_{0}\right]$ is a causal measure of the residual earnings inequality which can be estimated without 
additional identifying assumptions other than those used for the estimation of the mean causal returns. Hence the residual earnings inequality

$$
\mathrm{V}\left[\ln Y_{1}-\ln Y_{0}\right] \geq \mathrm{V}\left[\ln Y_{1}\right]-\mathrm{V}\left[\ln Y_{0}\right]
$$

can serve as an informative lower bound for the program risk if $\mathrm{V}\left[\ln Y_{1}\right]-\mathrm{V}\left[\ln Y_{0}\right]>$ 0 . However, it is important to note, that causal mean and variance effects are expost measures based of the random variable earnings (i.e. more precisely on the realization of this random variable). Thus the variance effect captures both individual income variation resulting from individual heterogeneity unknown to the econometrician, but known to the individual, income risk due to risk concerning the educational program (failure risk, matching risk of choosing the appropriate program etc.), and income risk due to the labor market conditions (e.g. macro shocks). Surprisingly, the aspect that educational choice is also based on risk evaluations and the trade-off between risk and return has been tackled only in a few studies. Notable exceptions are the papers by Belzil \& Hansen (2002) and Hogan \& Walker (2001), who model the individual schooling decision as a dynamic programming decision under uncertainty. Hartog \& Serano (2002) estimate the impact of income risk on the education decision on the basis of a static expected utility maximization calculus. They find out that income risk is a non-negligible determinant of the schooling decision. Heckman, Lochner \& Todd (2003) compute the internal return rate of education taking into account income risk about the future income stream. Using US Census data (1940-1990), they find that the internal rate decreases substantially if one accounts for income risk. However, none of the studies mentioned above tries to combine the idea of the potential outcome approach with the aspect of educational choice under uncertainty.

\subsection{School Quality and Returns to Education}

Causal return estimates are helpful to discriminate between successful and less successful programs. In particular, a comparison of the mean causal returns with the mean causal returns for the treated and the untreated may yield valuable information on how well students are selected into different educational programs. From an educational economics point of view, however, causal return estimates are only of limited value, because they do not provide any specific information on whether educational programs are to be (re-)designed to improve the students' labor mar- 
ket prospects. For the improvement of the design of educational programs, it is therefore of greater importance to investigate how certain aspects of educational programs (e.g. expenditures per student, class size, student-teacher ratio, enumeration of teachers, assessment test for applicants) have an effect on the labor market performance in later years.

For the US, Card and Krueger $(1992,1996)$ provide supporting empirical evidence for a positive link between school quality and subsequent earnings. ${ }^{4}$ For various methodological reasons, their results were questioned by a number of studies including Betts (1995), Heckman, Layne-Farrar \& Todd (1996) as well as Hanushek, Rivkin \& Taylor (1996). Using data for West Germany, Baumgartner (2004) investigates the impact of class size on early career earnings and finds no significant empirical evidence for this relationship.

Similar to the case of the return estimates, the problem of heterogeneity and selfselectivity arises here, too, such that good scholars are more likely to attend good schools. Hence, it is impossible to infer that the above average performance/earnings of a worker educated at a 'good' school is causally related to the higher quality of the educational input. It may rather be the result of a self-selection process. Whether the selectivity problem is severe for the case of Germany is at least doubtful, because the dominating public school system guarantees fairly equal standards in terms of the schools' endowments. However, the low variation across observational units in Germany is likely to aggravate the problem of finding significant empirical support for a positive link between quality and earnings. Nevertheless, an analysis on the causal link between the quality of educational attainment and individual labor market success on large scale micro-data would nicely complement studies on the link between school quality and the outcomes of learning (e.g. based on the PISA or TIMSS data).

\footnotetext{
${ }^{4}$ See also Brewer \& Ehrenberg (1999), Dale \& Krueger (2002), Light \& Strayer (2000) and the survey by Brewer \& Ehrenberg (1996).
} 


\section{Conclusion}

This paper surveys the empirical evidence on causal effects of education on earnings for Germany and compares alternative studies in the light of their underlying identifying assumptions. We point out, that given these assumptions, the various studies estimate rather different causal effects. But despite the substantial methodological differences, we have to conclude that the findings are quite robust and do not deviate substantially from each other. This also holds for the few studies which rely on ignorability conditions, regardless whether they use educational attainment as a continuous treatment variable or as a discrete treatment indicator. The classical IV estimates are somewhat less robust compared to the results obtained by the control function and ignorability approaches, and are sensitive to the instrument chosen.

Studies which additionally estimate the causal returns for the treated and the untreated indicate that the selection gain for graduates of the upper secondary school level is not significantly different from zero, if compared to the earnings of workers with intermediate secondary schooling. This at least raises some doubts about the effectiveness of the selection process at the early stage of the educational career.

In this survey we restricted ourselves to the estimation of the mean causal returns to education that have been estimated for Germany. However, in order to use the potential outcome approach for educational policy analysis, information beyond the mean effects of a treatment is often required. For example, the policy maker could be interested in the extent of variation of a certain educational treatment effect, or in the proportion of individuals who gain from schooling. Methods which try to estimate evaluation parameters beyond the mean treatment effects are discussed, for example, by Heckman, Smith \& Clements (1997), Chib and Hamilton (2000, 2002), and Carneiro, Hansen \& Heckman (2003).

Although the econometric evaluation literature offers a variety of sophisticated methods for the estimation of causal effects on the basis of non-experimental data, at the end, the choice and applicability of these estimators depend on the available data. In Germany, the information in the data is limited, if not marginal, for the purpose of estimating causal returns to education. In the future, a lot more effort should be taken in collecting appropriate and rich data sets, especially regarding the measurement of cognitive and non-cognitive skills, in order to give valid answers for 
questions in educational policy analysis. 


\section{References}

Angrist J., Imbens G., Rubin D. (1996), Identification of Causal Effects Using Instrumental Variables, Journal of the American Statistival Association, vol. 91, pp. $444-472$.

Baumgartner H. (2004), Are There Any Class Size Effects on Early Career Earnings in West Germany, dIW Discussion Paper, No. 417.

Becker S.O., Siebern-Thomas F. (2001), Returns to Education in Germany: A Variable Treatment Intensity Approach, economics Working Papers from European University Institute.

Belzil C., Hansen J. (2002), Earnings Risk and the Demand for Higher Education, IZA Discussion Paper 513.

Betts J.R. (1995), Does School Quality Matter? Evidence from the National Longitudinal Survey of Youth, Review of Economics and Statistics, vol. 77, pp. 231 -250 .

Blundell R., Dearden L., Sianesi B. (2005), Evaluating the Impact of Education on Earnings in the UK: Models, Methods and Results from the NCDS, Journal of the Royal Statistical Society, Series A, vol. 168, pp. 473 - 512, iFS Working Papers W03/20, Institute for Fiscal Studies.

Bound J., Jaeger D., Baker R. (1995), Problems with Instrumental Variables Estimation When the Correlation between Instruments and Endogenous Explanatory Variables is Weak, Journal of the American Statistical Association, vol. 90, pp. $443-450$.

Brewer D., Ehrenberg R. (1996), Does It Pay to Attend an Elite Private College? Evidence from the Senior Class of 1980, Research in Labor Economics, vol. 15, pp. 239-271.

Brewer E.E. D., Ehrenberg R. (1999), Does It Pay to Attend an Elite College? Cross Cohort Evidence on the Effects of College Type on Earnings, Journal of Human Resources, vol. 34, pp. 104-123.

Card D. (1995), Earnings, Schooling and Ability Revisited, Research in Labor Economics, vol. 14 , pp. $23-48$. 
Card D. (2001), Estimating the Returns to Schooling: Progress on Some Persistent Econometric Problems, Econometrica, vol. 69, pp. 1127-1160.

Card D., Krueger A. (1992), Does School Quality Matter: Returns to Education and the Characteristics of Public Schools in the United States, Journal of Political Economy, vol. 109, pp. 1-40.

Card D., Krueger A. (1996), Labor Market Effects of School Quality: Theory and Evidence, in: G. Burtless, ed., Does Money Matter? The Link Between Schools, Student Achievement and Adult Success, Brookings Institution, Washington D.C., pp. $97-140$.

Carneiro P., Hansen K., Heckman J. (2003), Estimating Distributions of Treatment Effects with and Application to the Returns to Schooling and Measurement of the Effects of Uncertainty on Schooling Choice, International Economic Review.

Chib S., Hamilton B.H. (2000), Bayesian Analysis of Cross-section and Clustered Treatment Models, Journal of Econometrics, vol. 97, pp. 25 - 50.

Chib S., Hamilton B.H. (2002), Semiparametric Bayes Analysis of Longitudinal Data Treatment Models, Journal of Econometrics, vol. 110, pp. 67-89.

Dale S., Krueger A. (2002), Estimating the Payoff to Attending a More Selective College: An Application of Selection on Observables and Unobservables, Quarterly Journal of Economics, vol. 117, pp. 1491-1528.

Franz W. (2002), Arbeitsmarktökonomik, 5. Auflage, Springer, Berlin.

Groot W., van den Brink H.M. (2000), Overeducation in the labor market: a metaanalysis, Economics of Education Review, vol. 19(2), pp. 149-158.

Hanushek E., Rivkin S., Taylor L. (1996), Aggregation and the Estimated Effects of School Resources, The Economic and Social Review, vol. 78, pp. $611-627$.

Hartog J., Serano L. (2002), Earnings Risk and Demand for Higher Education: A Cross-Section Test for Spain, IZA Discussion Paper, vol. 641.

Heckman J. (1979), Sample Selection as a Specification Error, Econometrica, vol. 47, pp. $153-161$. 
Heckman J. (1997), Instrumental Variables: A Study of Implicit Behavioral Assumptions Used in Making Program Evaluations, Journal of Human Resources, vol. 32 , pp. $441-462$.

Heckman J., Layne-Farrar A., Todd P. (1996), Human Capital Pricing Equations with an Application to Estimating the Effect of Schooling Quality on Earnings, Review of Economics ans Statistics, vol. 78, pp. $562-610$.

Heckman J., Li X. (2003), Selection Bias, Comparative Advantage and Heterogeneous Returns to Education: Evidence for China in 2000, discussion paper Nr. 829, IZA.

Heckman J., Lochner L., Todd P. (2003), Fifty Years of Mincer Earnings Regressions, NBER Working Paper, vol. 9732.

Heckman J., Robb R. (1986), Alternative Methods for Evaluating the Impact of Intervention, Longitudinal Analysis of Labor Maket Data.

Heckman J., Smith J., Clements N. (1997), Making the Most Out of Programme Evaluations and Social Experiments: Accounting for Heterogeneity in Programme Impacts, Review of Economic Studies, vol. 64, pp. $487-535$.

Heckman J., Vytlacil E. (1998), Instrumental Variables Methods for the Correlated Random Coefficient Model: Estimating the Rate of Return to Schooling When the return is Corelated with Schooling, Journal of Human Resources, vol. 23, pp. $974-987$.

Heckman J., Vytlacil E. (2005a), Econometric Evaluation of Social Programs, in: J. Heckman, E. Leamer, eds., Handbook of Econometrics, Vol. 6,, Elsevier Science, Amsterdam.

Heckman J., Vytlacil E. (2005b), Structural Equations, Treatment Effects, and Econometric Policy Evaluation, Econometrica, vol. 73, pp. 669 - 738.

Hogan V., Walker I. (2001), Education Choice under Uncertainty, working Paper, University College Dublin / University of Warwick.

Ichino A., Winter-Ebmer R. (1999), Lower and Upper Bounds of Returns to Schooling: An Exercise in IV Estimation with Different Instruments, European Economic Review, vol. 43, pp. 889 - 901. 
Ichino A., Winter-Ebmer R. (2004), The Long Run Educational Costs of World War II, Journal of Labour Economics, vol. 22, pp. 57-86.

Imbens G. (2004), Nonparametric Estimation of Average Treatments Effects Under Exogeneity, Review of Economics and Statistics, vol. 86, pp. $4-29$.

Imbens G., Angrist J. (1994), Identification and Estimation of Local Average Treatment Effects, Econometrica, vol. 62, pp. $467-476$.

Jochmann M., Pohlmeier W. (2003), The Causal Effect of Overeducation on Earnings: Evidence from a Bayesian Approach, in: F. Büchel, A. de Grip, A. Mertens, eds., Overeducation in Europe: Current Issues in Theory and Policy, Edward Elgar, Cheltenham, pp. 93 - 108.

Jochmann M., Pohlmeier W. (2004), Der Kausaleffekt von Bildungsinvestitionen: Empirische Evidenz für Deutschland, in: W. Franz, H.J. Ramser, M. Stadler, eds., Bildung, Mohr Siebeck, Tübingen, pp. $1-24$.

Kling J. (2001), Interpreting Instrumental Variables Estimates of the Returns to Schooling, Journal of Business and Economic Statistics, vol. 19, pp. 358 - 364.

Lauer C., Steiner V. (2000), Returns to Education in West Germany, zEW Discussion Paper 00-04.

Lechner M. (2001), Identifiation and Estimation of Causal Effects of Multiple Treatments under the Conditional Indepencence Assumption, in: M. Lechner, F. Pfeiffer, eds., Econometric Evaluation of Labour Market Policies, Physica/Springer, Heidelberg, pp. 43-58.

Light A., Strayer W. (2000), Determinants of College Completion: School Quality or Student Ability?, Journal of Human Resources, vol. 35, pp. 299-332.

Maier M. (2004), Causal Effects of Education in Germany, unpublished Discussion Paper, ZEW, Mannheim.

Maier M., Pfeiffer F., Pohlmeier W. (2003), Overeducation and Individual Heterogeneity, in: F. Buechel, A. de Grip, A. Mertens, eds., Overeducation in Europe: Current Issues in Theory and Policy, Edward Elgar, Cheltenham.

Maier M., Pfeiffer F., Pohlmeier W. (2004), Returns to Education and Individual Heterogeneity, ZEW Discussion Paper, (04-34). 
Pfeiffer F. (1994), Selbständige und abhängige Erwerbstätigkeit, Campus Verlag, Frankfurt.

Pischke J., DiNardo J. (1997), The Return to Computer Revisited: Have Pencils Changed the Wage Structure Too?, Quarterly Journal of Economics, vol. 112, pp. 291-303.

Pischke J., Von Wachter T. (2005), Zero Returns to Compulsory Schooling in Germany: Evidence and Interpretation, iZA DP No. 1645.

Pischke J.S., Krueger A. (1995), A Comparison of East and West German Labor Markets Before and After Unification, in: R. Freeman, L. Katz, eds., Differences and Changes in Wage Structures, Chicago University Press, pp. 405-445.

Pohlmeier W. (2004), Bildungsrenditen, in: Investitionsgut Bildung, Workshop "Investition in Humankapital", Bonn , June 7th, 2004, Bundesministerium für Bildung und Wissenschaft, pp. $17-20$.

Pohlmeier W., Flossmann A. (2005), The Potential Outcome of Schooling: Individual Heterogeneity, Program Risk and Residual Wage Inequality, paper presented at the conference 'Heterogenous Labor and Education', DFG Research Group 454, Mannheim, September 12-13, 2005.

Powell J.L. (1994), Estimation of Semiparametric Models, in: R.F. Engle, D.L. McFadden, eds., Handbook of Econometrics, chap. 41, Elsevier Science, pp. 2443-2521.

Roy A. (1951), Some Thoughts on the Distribution of Earnings, Oxford Economic Papers, vol. 3, pp. $135-146$.

Rubin D.B. (1974), Estimating Causal Effects of Treatments in Randomized and Non-Randomized Studies, Journal of Educational Psychology, vol. 66, pp. 688 $-701$.

Schnabel I., Schnabel R. (2002), Family and Gender Still Matter: The Heterogeneity of Returns to Education in Germany, university of Mannheim, unpublished working paper.

Skarupke R. (2005), Renditen von Bildungsinvestitionen. Paneldaten-Schätzungen für die Bundesrepublik Deutschland, Peter Lang, Frankfurt am Main. 
Staiger D., Stock J.H. (1997), Instrumental Variables with Weak Instruments, Econometrica, vol. 65, pp. $557-586$.

Steiner V., Lauer C. (2000), Private Erträge Von Bildungsinvestitionen in Deutschland, ZEW Discussion Paper, vol. 00-18.

Vytlacil E. (2002), Independence, Monotonicity, and Latent Variable Models: An Equivalence Result, Econometrica, vol. 70, pp. 331 - 341.

Wooldridge J.M. (2000), Introductory Econometrics: A Modern Approach, SouthWestern College Publishing.

Wooldridge J.M. (2002), Econometric Analysis of Cross Section and Panel Data, MIT Press, Cambridge, MA.

Wooldridge J.M. (2004), Estimating Average Partial Effects under Conditional Independence Assumptions, unpublished working paper, Department of Economics, Michigan State University. 